\title{
Geotechnical properties of reinforced clayey soil using nylons carry's bags by products
}

\author{
Nahla Salim ${ }^{1, *}$, Kawther Al-Soudany ${ }^{1}$, and Nora Jajjawi ${ }^{1}$ \\ ${ }^{1}$ University of Technology, Baghdad, Iraq
}

\begin{abstract}
All structures built on soft soil may experience uncontrollable settlement and critical bearing capacity. This may not meet the design requirements for the geotechnical engineer. Soil stabilization is the change of these undesirable properties in order to meet the requirements. Traditional methods of stabilizing or through in-situ ground improvement such as compaction or replacement technique is usually costly. Now a safe and economic disposal of industrial wastes and development of economically feasible ground improvement techniques are the important challenges being faced by the engineering community. This work focuses on improving the soft soil brought from Baghdad by utilizing the local waste material for stabilization of soil, such as by using "Nylon carry bag's by product " with the different percentage and corresponding to $1 \%, 3 \%$ and $5 \%$ ( the portion of stabilizer matters to soil net weight) of dried soil. The results indicated that as Nylon's fiber content increases, the liquid limit decreases while the plastic limit increases, so the plasticity index decreases. Furthermore, the maximum dry density decreases while, the optimum moisture content increases as the Nylon's fiber percentage increases. The compression index ( decreases as the Nylon's fiber increases and provides a maximum of $43 \%$ reduction by adding $5 \%$ nylon waste material. In addition, the results indicated that, the undrained shear strength increases as the nylon fiber

increases.
\end{abstract}

\section{Introduction}

Stabilization is the method of blending different soils or adding additives to soil to improve the characteristic of the soil such as strength, durability, gradation and plasticity which making the soils more stable. The main objective of stabilization can be listed:

- Decrease cohesiveness (Plasticity)

- Decrease volume expansion or compressibility

- Increase strength.

There are different methods of soil stabilization, which can be categorized into:

a)- Mechanical stabilization

b)-Chemical stabilization

c)- Combined between mechanical and chemical stabilization.

Mechanical stabilization can be achieved either by compaction which causes an interlocking of the soils particle, or by dewatering of wet soil (if water drains out of soil, the soil becomes strong)or by changing in gradation size of soil by adding different types of material such as fine or aggregate and compacting the mixture .

Chemical stabilization, which depends mainly on the chemical reaction between the additive material (cementation) and the soil minerals (pozzolanic material) to a chieve desired effect. Cement, lime, fly ash, bitumen and combination of these can be used for this type of stabilization. Usually stabilized soils have higher strength and lower compressibility than the native soils. Many researchers used these types of stabilization and .

Soil reinforcement is one method of soil improvement in geotechnical engineering application. The main issues of reinforcement first developed by using tensile resisting materials into the soil to improve the strength of soil and increase its stability. In general, soils can withstand high compressive strength but cannot withstand the tensile strength. So the main objective of soil reinforcement is to make soils to absorb tensile loads and shear stresses by using reinforcement elements. So the stability of geotechnical structure can be achieved by randomly using reinforcement and distributed throughout the soil element. This method was used early in ancient times when reeds, sops, straws, and timber were used in reinforcing the soils element by mixing this material with soils to enhance the soil properties. Soil reinforcement can be categorized into Macro-reinforcement and Micro-reinforcement.

The Macro-reinforcement included woven and nonwoven reinforcement and widely used in construction industries Micro-reinforcement were used in which conduct by using randomly small reinforcing elements into soil mass with the uniform distribution .

\section{Soil fiber reinforcement}

In general soils have low tensile strength and highly affected by environmental conditions. Soil reinforcement can be defined as a method to improve the physical and 
mechanical properties of the soil. The primary purpose of reinforcing soil mass is

1- to improve its stability,

2- to increase its bearing capacity, and

3 - to reduce settlements and lateral deformations [12].

There are different soil reinforcement methods, such as:

stone columns [13], root piles, soil nailing and reinforced earth. Reinforced earth is a composite material consisting of compacted backfill and man-made reinforcing materials such as fibrous materials (geosynthetic and randomly distributed fibers). The idea of reinforcing soils using fibers is one that has been in use for a long time[12]. Initial developments in soil reinforcement led to the use of plant roots and straws in walls made from soil bricks to improve their mechanical properties. Fiber reinforcement in soils acts as homogeneous materials in composites which are fibers, and have high tensile strength included in a soil matrix. Tensile resistance in the fibers affects the shear stress in the soil and contributes greater strength to the composites soil.

Nylon fibers were used to reinforce silty clay soil with different degree of compaction by [14] they studied the relative strength gained in terms of unconfined compression and concluded that the effect of adding nylon fibers is significantly higher on the residual strength of soil rather than on the peak strength. The results obtained showed that the strain at the peak increases with the increasing the amount of fibers. The result indicated that the peak and the residual strength of the soils compacted up to $93 \%$ are significantly more than the samples compacted at the higher densities. Reinforcement by fiber was used in waste containment soil liners by [15]. They illustrated the role of fiber reinforcement in reducing crack development in compacted clay samples and their effect on the hydraulic conductivity. The maximum crack reduction observed was approximately $90 \%$ for a fiber content of $0.8 \%$. It was found that the hydraulic conductivity of clay liners increased with increasing fiber content.

Reference [16] performed a laboratory test to study the properties of using waste of nylon carpet fiber in reinforcing sandy silt soil. The results revealed that compressive strength increased by $204 \%$ using $3 \%$ carpet fibers and the ductility of the soil was mentioned by the authors. In addition, field tests have shown that shredded carpet waste fibers of $70 \mathrm{~mm}$ long can be used into the soil with special equipment. The availability and the low cost fibers from carpet waste could lead to wider use of fiber reinforced soil and more cost-effective in construction.

Reference[17] conducted the experimental works mainly on the compressive strength and swelling properties of clay reinforced with metal fiber. Different percentages of fibers mixed with soil were used to prepare specimens to be tested. It was found that both peak strength and strain at failure increased with increasing fiber content while swelling pressure and swelling potential decreased with the increase of fiber content. The suitable percentage of fiber content was found to be $8 \%$.

Reference [18] improved the property of expansive soil by the combined application of lime and geosynthetic reinforcement using experimental approach. A series of unconfined compression tests have been conducted on soil mixed with different percentages of lime $(2,4,8,12$ and $16 \%)$ and for different curing periods $(3,7,14$ and 28 days). Significant improvements in strength with increase in lime-content have been observed. At 2, 4, 8, 12 and $16 \%$ of lime content the strength improvements were found to be $2.5,3.5,8.4,8.7$ and 8.5 times respectively than that of untreated soil. Reference [19] pointed out that, based on the total and effective stresses, the increase in the content of nylon fiber causes an increase in the shear strength parameters of clay.

Significant improvements in strength with increase in lime-content have been observed. At 2, 4, 8, 12 and 16\% of lime content the strength improvements were found to be $2.5,3.5,8.4,8.7$ and 8.5 times respectively than that of untreated soil. Reference [19] pointed out that, based on the total and effective stresses, the increase in the content of nylon fiber causes an increase in the shear strength parameters of clay.

\section{Laboratory studies}

In this part, experimental work was conducted using standard procedures, the untreated samples were tested for their classification and index properties, as well as their consistency properties. Furthermore, the testing program conducted on the clayey soil samples stabilized with different percentages of recycled nylon strips, included Atterberg's limits, Specific Gravity, Static compaction, vane shear test and consolidation test.

The Atterberg Limits: The Atterberg limits are determined as follows:

Liquid limit (L.L): Casagrande Method according to ASTM [20]. The liquid limit test was conducted on samples passing $0.425 \mathrm{~mm}$ (No.40) sieve, Clayey soils with $(0,1,3,5) \%$ waste material taken from carry bag manufactured by-product, using Casagrande's liquid limit apparatus.

Plastic limit (P.L): ASTM [20]

The plastic limit test was performed on samples passing $0.425 \mathrm{~mm}$ (No.40) sieve, Clayey soils with $(0,1,3,5) \%$ nylon carry bags by product. Specific Gravity: (ASTM [21] ) The specific gravity (GS) test was carried out on the soil in accordance with ASTM [21]

Compaction Test: (ASTM [22] ) This test is used to determine the relationship between the moisture content and the dry density of a soil using standard proctor method.

Vane shear test: ASTM [23] "Standard Test Method for Field Vane Shear Test in Cohesive Soil.

Consolidation: (ASTM [24]) This test is carried out according to ASTM D 2435 - Standard test.

\section{Materials used}




\subsection{Soil}

The soil sample used for this study was brought from Baghdad city and transported to the soil mechanics laboratory, University of Technology where soil test has been conducted. The soil grain size distribution is shown Figure (1). The chemical and physical properties of natural soil are listed in Table (1).

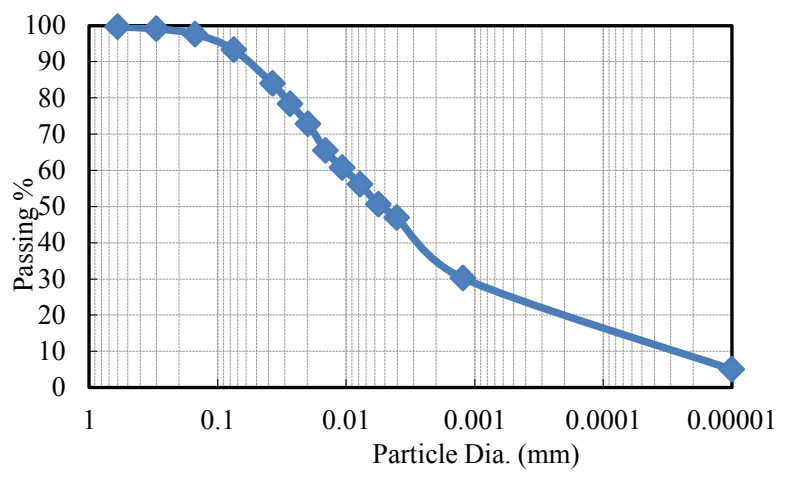

Fig. 1. Grain size distribution of clayey soil used

Table 1. Engineering properties of the used soil.

\begin{tabular}{|l|c|}
\hline \multicolumn{1}{|c|}{ Index property } & Value \\
\hline Liquid limit \%(LL) & 40 \\
\hline Plastic limit \%(PL) & 19 \\
\hline Plasticity index \%(PI) & 21 \\
\hline Specific gravity (Gs) & 2.69 \\
\hline Gravel (larger than $2 \mathrm{~mm}) \%$ & 0 \\
\hline Sand (0.06 to $2 \mathrm{~mm}) \%$ & 6.5 \\
\hline silt (0.005 to 0.06mm)\% & 43.5 \\
\hline Clay (less than 0.005mm)\% & 3.3 \\
\hline Gypsum content \% & 50 \\
\hline SO3 content \% & 2.92 \\
\hline Soil Symbols (USCS) & $\mathrm{CL}$ \\
\hline
\end{tabular}

\subsection{Nylon fiber materials}

This material commonly used for the shopping bag, storage and marketing for various purposes due to its most advantage character of less volume and weight. Most of these nylon carry bag by-products are especially made for spot use, having short life span and are being discarded immediately after use. With the few reasons cited above, it is very important that we find ways to reutilize these nylon carry bags by- product wastes. Therefore, the investigation and attempt have been carried out to demonstrate the potential of reusing these nylon wastes as soil reinforcement for improving the subgrade soils. The nylon waste was collected from nylon carry bag factory as the by-product of carry bags and made into strips using a secateurs and mill machine of different aspect ratios as shown in Figure (2). The used Nylon's fiber properties shown in Table (2).

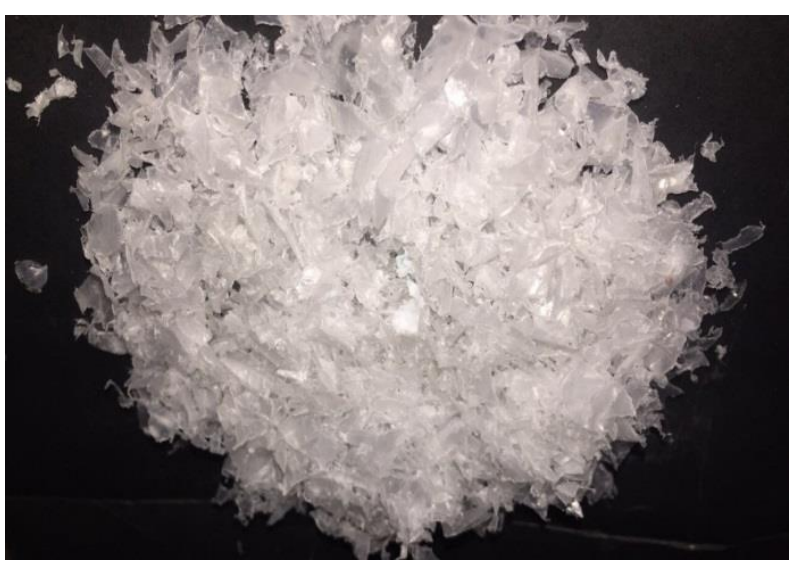

Fig. 2. Nylon's fiber used in experiments.

Table 2. Physical and engineering properties of the nylon's fiber used.

\begin{tabular}{|c|c|}
\hline Index Properties & Index Values \\
\hline Specific gravity & $0.98 \mathrm{~g} / \mathrm{cm}^{\wedge} 3$ \\
\hline Alkali conten & Nil \\
\hline Sulphate content & Nil \\
\hline Air entrainmen & $0.23 \%$ Air content will not \\
\hline Chloride content & Polymer Polypropylene \\
\hline Constituents & 17 micron \\
\hline Fibre diamete & $225 \mathrm{~mm}$ \\
\hline Fibre length $/ \mathrm{kg}$ \\
\hline Surface area & $3400-3800 \mathrm{MPa}$ \\
\hline Young modulus & Min $350 \mathrm{MPa}$ \\
\hline Tensile strength & $160 \mathrm{C}$ \\
\hline Melting point & \\
\hline
\end{tabular}

\section{Presentation and discussions of re- sults}

\subsection{Effect on compaction characteristics}

The effect of adding randomly different percentage of nylon fiber on compaction behavior of improved soils was clearly shown in Figures (3), (4), (5) and (6). Figure (3) shows the change of dry unit weight with water content of the intact soil. The compaction curve indicated that the maximum dry unit weight of natural soil is 18.04 $\mathrm{kN} / \mathrm{m} 3$ corresponding to $14.62 \%$ optimum water content. Figure(4) shows the effect of adding a different percentage of Nylon fiber on the maximum dry unit weight and the optimum moisture content. The outcome reveals that as the Nylon fiber increases the maximum dry unit weight decreases and the optimum moisture content increases. The reduction in maximum dry unit weight can be attributed to the replacement of soil by the nylon's fiber in the prepared soils, which has relatively lower specific gravity compared to that of the soils. 


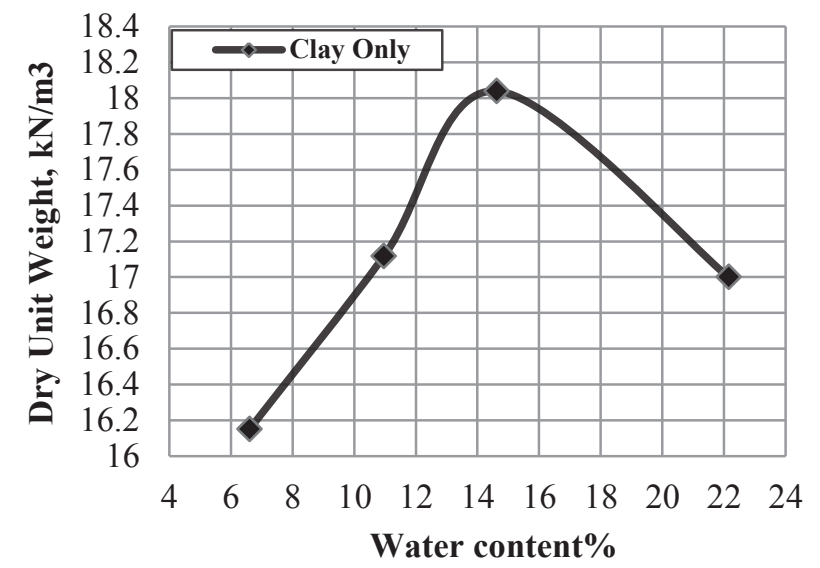

Fig. 3. Dry unit weight versus water content.

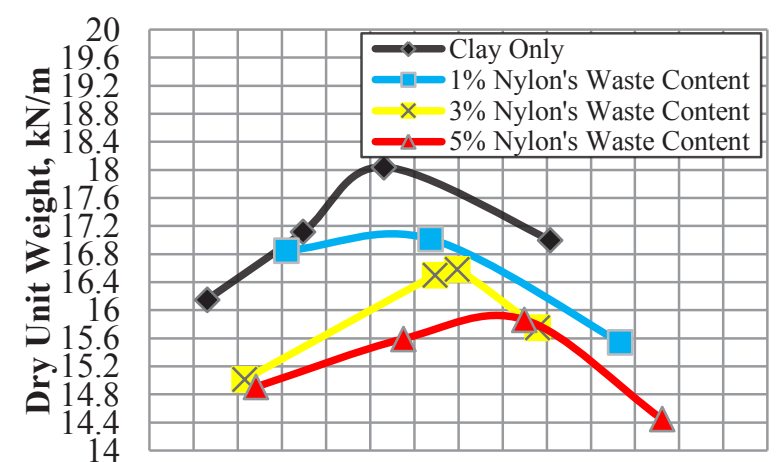

$4 \quad 6 \quad 8 \quad 101214161820222426283032$

Water Content\%

Fig. 4. Dry unit weight- water content at different percentage of nylon's fiber.

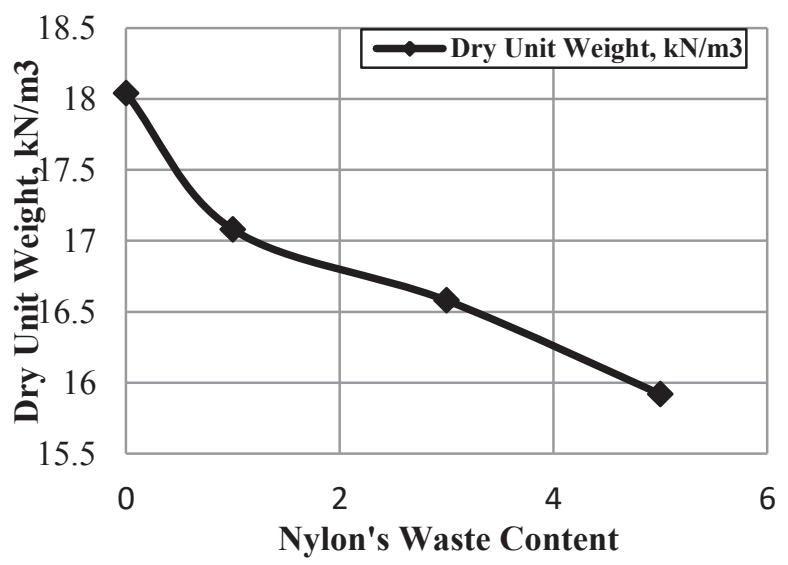

Fig. 5. Variation of the maximum dry unit weight with nylon's fiber percent.

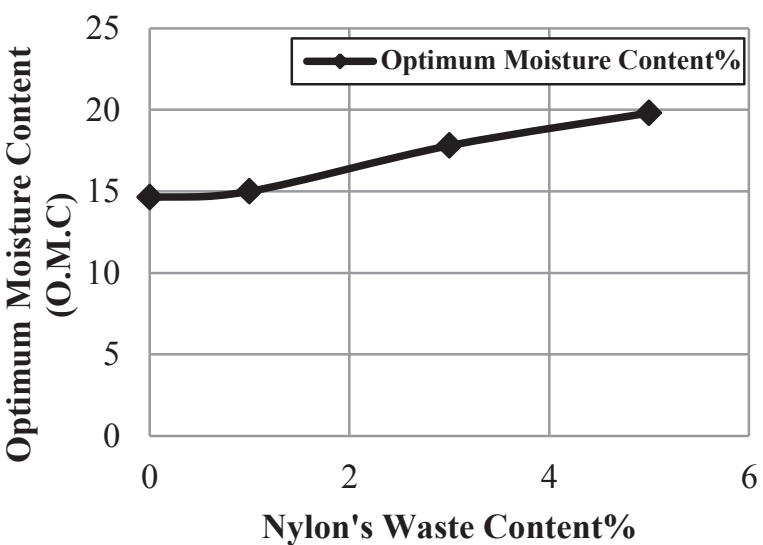

Fig. 6. Variation of the optimum moisture content with nylon's fiber percent.

\subsection{Effect on Atterberg's limits}

Figures (7), (8) and (9) show the effect of adding a different percentage of nylon fiber on consistency limits (LL, PL and PI), respectively. It is clearly shown, that the liquid limits (LL) decrease with increase in percentage of nylon fiber while the plastic limits (PL) increase with increase in nylon's plastic fiber. So as a result to change in liquid limit and plastic limit, noticeable decrease in the plasticity index as the nylon plastic fiber increases. This behavior ensured that this additive is considered as a granular binder.

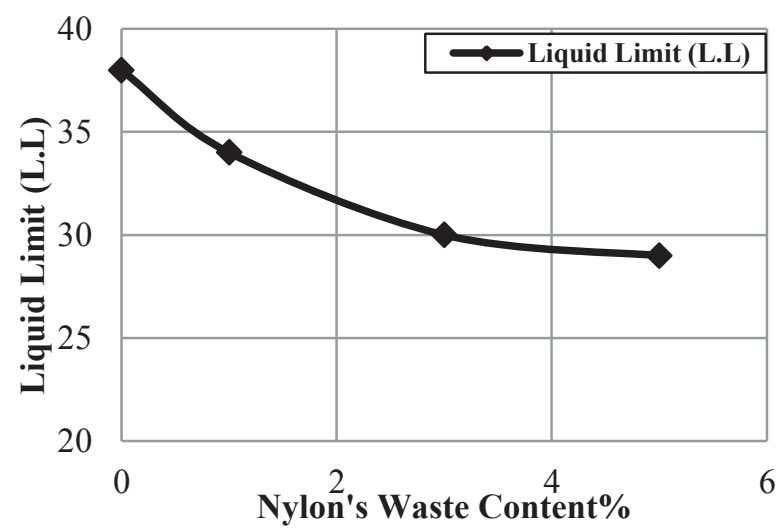

Fig. 7. Effect of nylon's fiber additive on liquid Limit.

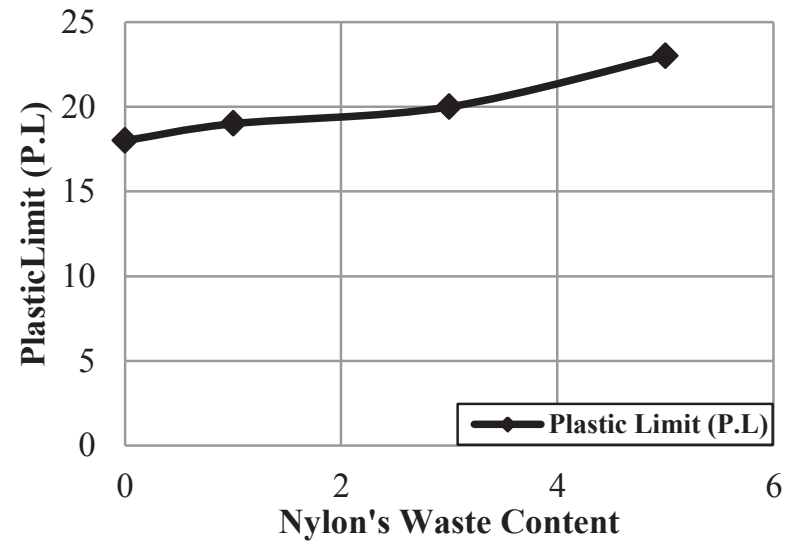

Fig. 8. Effect of nylon fiber on plastic limits 


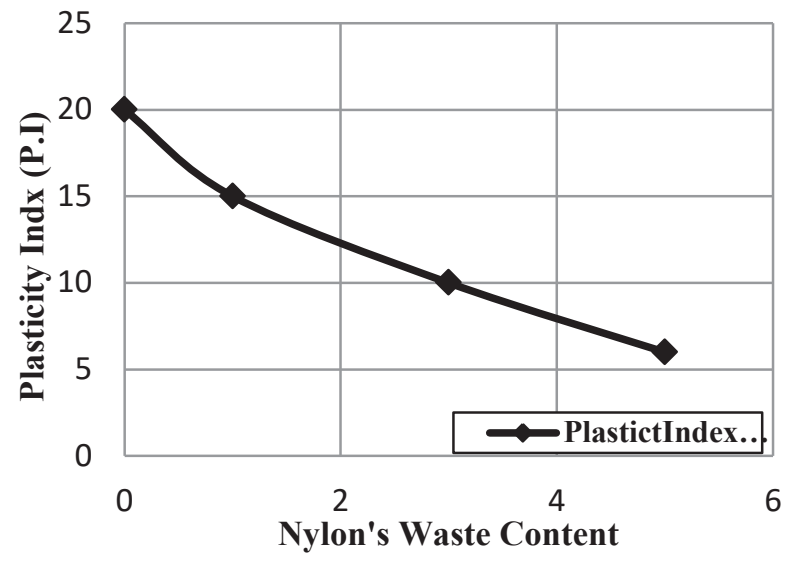

Fig. 9. Effect of nylon's fiber on plasticity index.

\subsection{Effect on specific gravity}

Figure (10) demonstrates the specific gravity values of the soil-mixed with the different percentage of nylon's fiber. It is clearly shown a reduction in specific gravity with the an increase in nylon fiber due to the low values of the specific gravity of nylon fiber.

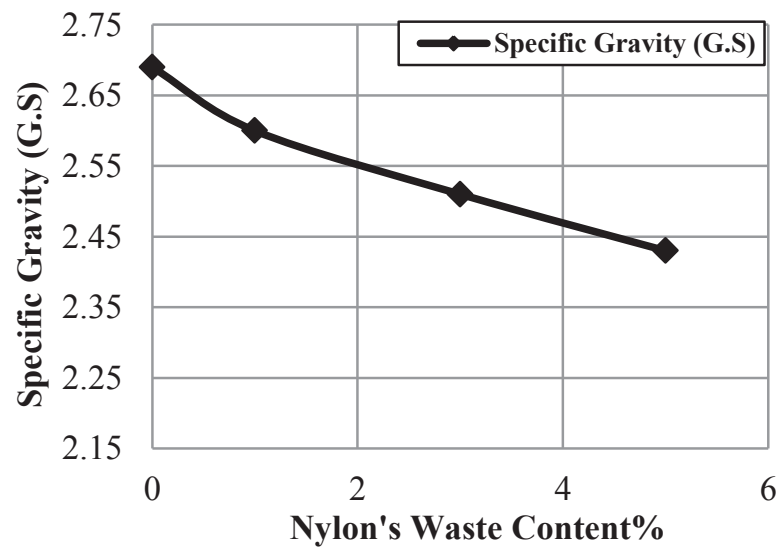

Fig. 10. Specific gravity with different $\%$ of nylon's carry bags by product.

\subsection{Effect on unconfined compressive strength}

The results of vane shear on stabilized soils with $(1,3,5)$ $\%$ nylon fiber are presented in (Figure 11). Undrained shear strength obtained from these tests show its linear increase with nylon fiber concentration up to $5 \%$ for all of the clayey soil used. The Vane shear test was also used to estimate the undrained shear strength of intact fully saturated clays. The test is:relatively simple, quick and provides a cost-effective way of estimating the soil shear strength; therefore, it is widely used in geotechnical investigations. The results of the test are not reliable if clay contains silt or sand. To prepare samples for vane shear test the specimens were prepared at a dry unit weight of $(15 \mathrm{kN} / \mathrm{m} 3)$ and moisture content of (25\%), air dry soil was mixed with the required amount-of-distilled water-to give initial water content. The soil was mixed thoroughly by hand and stored in a desiccator for 24 hours to get uniform -moisture-distribution. Static compaction method was followed for preparation of soil samples using a special mold and a compression testing machine. Load was applied statically to the soil sample at a compression rate of $0.04 \mathrm{~mm} / \mathrm{sec}$. until the depth of penetration approached the required height. The load was maintained on the specimen for about five minutes after reaching the required height to prevent the occurrence of rebound after static load removal.

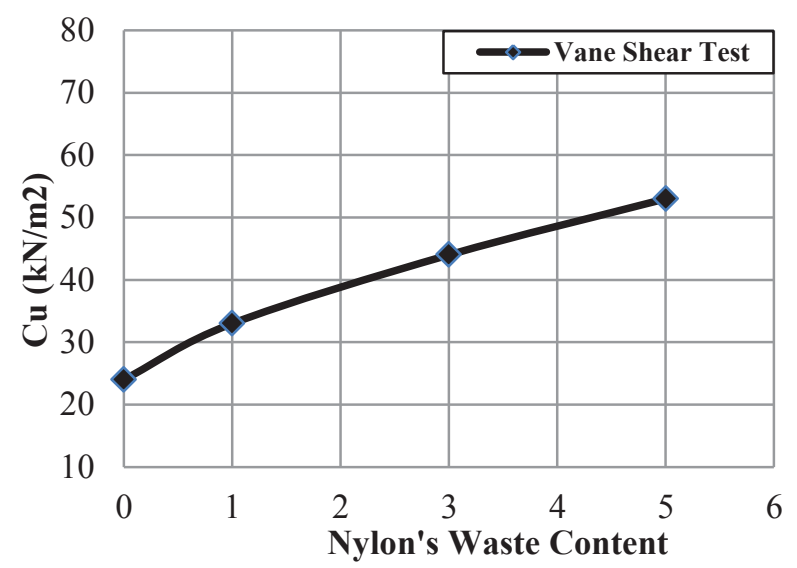

Fig. 11. The effect of nylon's fibers content addition on undrained shear strength of soil.

\subsection{Effect on compressibility characteristics}

In this study, the compressibility tests of clayey soils were carried out using one-dimensional consolidation test (Oedometer test). The results of standard consolidation test of soils are presented as a relation between the void ratios versus the logarithm of effective stress curve as shown in Figures (12). The loading compression curves and the recompression curves are an approximate linear. The values of compression index $(\mathrm{Cc})$ and recompression index $(\mathrm{Cr})$ are given in Table (3). For consolidation test the specimens were prepared at a dry unit weight of (15 $\mathrm{kN} / \mathrm{m} 3)$ and moisture content of $(25 \%)$ using static compaction, air dry soil was mixed with the -distilled water-to give initial moisture content.

Table 3. Results of consolidation test for treated soil.

\begin{tabular}{|c|c|c|c|}
\hline Nylon's Fiber \% & $\boldsymbol{C}_{\boldsymbol{c}}$ & $\boldsymbol{C}_{\boldsymbol{r}}$ & $\boldsymbol{C}_{\boldsymbol{c}} / \boldsymbol{C}_{\boldsymbol{r}}$ \\
\hline $0 \%$ & 0.157995 & 0.03336 & 4.736111 \\
\hline $1 \%$ & 0.142193 & 0.044138 & 3.221569 \\
\hline $3 \%$ & 0.116362 & 0.039413 & 2.952381 \\
\hline $5 \%$ & 0.101969 & 0.035086 & 2.90625 \\
\hline
\end{tabular}




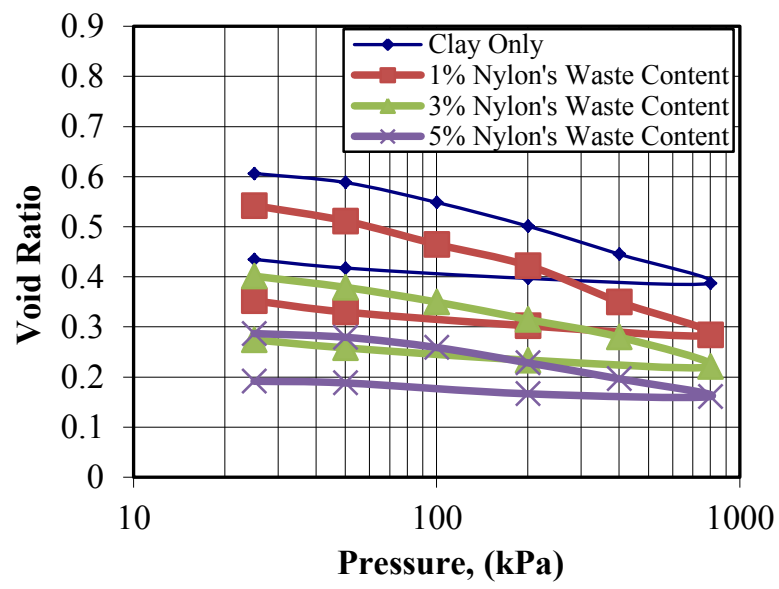

Fig. 12. Relation of e-log $\mathrm{p}$ for untreated and treated soils with nylon addition.

\section{Conclusions}

The application of recycled fiber has become the new issue due to environmental benefits and cost effect of geofiber. This study focuses on the effect of inclusion randomly nylon carry bag by-products as a reinforcing material on physical and mechanical properties of clayey soils. And by analyzing the experimental results, the following conclusions were made:

1- The addition of randomly distributed nylon waste resulted in reducing liquid limits and slightly increasing plastic limits. These behaviors cause a reduction in plasticity index, this means increase in the workability which enhances the physical properties of soils.

2- The inclusion of nylons waste to the clay soil causes a reduction in the maximum dry unit weight and an increase in the optimum moisture content, the compaction curves go down and shift to the right side.

3- The nylon waste material mixed with clayey soils causes a reduction in specific gravity as the percentage of waste material increase.

4- The compression index $\left(c_{C}\right)$ decreases as nylon fiber increases and the maximum decrease is approximately $35 \%$ by adding $5 \%$ of nylon's waste.

\section{References}

1. B.M. Daz (2002) "Principles of Geotechnical Engineering", 5th Edition, Wadsworth Group,

California, USA

2. D.N. Little (1995)"Handbook for Stabilization of
Pavement Subgrades and Base Courses with Lime", Kendal/Hunt, Lowa.

3. N. L. Dallas, Summary of Finding Web Address; (WWW.lime.org/SOIL.PDF), 1 (1999)

4. C.M. Geiman, M.Sc. thesis, Virginia Polytechnic Institute andvState University, at Blacksburg, VA (2005)

5. N. K..Al-Saoudi, F. H. Rahil \& K. Y. ALSoudany, Uotechnology Journal, 29,15 (2011)

6. K. Harichan, M. Ghrici, S. Kenai, and K. Grine, Geotech Geol Eng, 29 (5), 759 (2011b)

7. N. Kumar, S. Swain, U. Sahoo Geotech Geol Eng, 24, 2 DOI 10.1007/s10706-012-9532-3 (2012)

8. H. Vidal, "The Principle of Reinforced Earth", Highway Research Record, 282, 1-16 (1969)

9. H. Gregory, S.Chill, In: 6th Int conf geosynt, Atlanta, USA (1998)

10. R.M.Koerner, GCLs" Fourth Edition, Prentice Hall, New, Jersey (1999)

11. I.M.C.F.G.Falorca, M.I.M.,Pinto, "Effect of short, randomly distributed polypropylene microfibres on shear strength behaviour of soils" Geosynthetics International, 18, 2-11(2011)

12. D.R. Freitag, J. Geotech . Geoenviron Eng., ASCE, 112 (1986)

13. M.Y. Fattah,, B.S.Zabar, and H.A. Hussan,IJG ASCE, 16, 4 (2016)

14. S.Kumar, and E.Tabor, EJGE, 8 (2003)

15. J. Miller, S.Rifai, J Environ Eng ASCE, 130:9815 (2004)

16. J.Murray ,D. Frost, Y.Wang, Trans Res Rec, 1714:9 17 (2004)

17. S.I. Al-Azzo,S.M., and T.A. Salim, "Compressive strength and swelling properties of randomly distributed fiber reinforced clayey soil"(2007)

18. D. Baglari, and S.K. Dash, "Improvement of Expansive soil by lime and reinforcement" Proceedings of Indian Geotechnical Conference December 22-24, Roorkee (2013)

19. A.R.Estabragh, A.T.Bordbar, and A.A. Javadi, Geotech Geol Eng 31:501-510 (2013)

20. ASTM D 4318-00, "Standard test methods for liquid limit, plastic limit, and plasticity index of soils", American Society for Testing and Materials.

21. ASTM D 854-00: "Standard test method for specific gravity of soil solids by pycnometer", American Society for Testing and Materials.

22. ASTM D698-00: "Standard test methods for laboratory compaction characteristics of using standard effort (600 kN-m/m3)", American Society for Testing and Materials.

23. ASTM D2573- 01: "Standard Test Method for Field Vane Shear Test in Cohesive Soil"

24. ASTM D2435: "Standard Test Method for OneDimensional Consolidation Properties of Soils", American Society for Testing and Materials. 